Appendix A. Supporting Information:

A Biophysicochemical Model for NO Removal by the Chemical Absorption-Biological Reduction Integrated Process

Jingkai Zhao, ${ }^{\dagger}$ Yinfeng Xia,${ }^{\dagger}$ Meifang $\mathrm{Li},{ }^{\dagger}$ Sujing Li, ${ }^{\dagger}$ Wei $\mathrm{Li}^{*}{ }^{\dagger}$ and Shihan Zhang,,${ }^{*}$

${ }^{\dagger}$ Key Laboratory of Biomass Chemical Engineering of Ministry of Education, Institute of Industrial Ecology and Environment, College of Chemical and Biological Engineering, Zhejiang University, Yuquan Campus, Hangzhou 310027, China

\$College of Environment, Zhejiang University of Technology, Hangzhou 310032, China

Corresponding Authors:

*(W.L.) Tel: +86 5718795 2513; E-mail address: w_li@zju.edu.cn.

*(S.H.Z.) Tel: +86 5718832 0853; E-mail address: skyzhang@zju.edu.cn.

10 Pages

3 Tables

1 Figure 


\section{Physicochemical constants}

Based on the two-film theory, the overall liquid-phase mass transfer resistance is the sum of the individual liquid- and gas-phase resistances, and can be determined by:

$$
\frac{1}{K_{L, i}}=\frac{1}{k_{G, i}}+\frac{1}{E_{i} k_{L, i}}(i=\mathrm{X}, \mathrm{Y})
$$

where $k_{G}$ is the individual gas-phase mass transfer coefficient, $k_{L}$ is the individual liquid-phase mass transfer coefficient, $E_{i}$ is the enhanced factor for the gas absorption coupled with chemical reaction (1) or (2). The individual gas- and liquid-phase mass transfer coefficients $\left(k_{G}, k_{L}\right)$ could be calculated using the equations developed by Onda, ${ }^{1,2}$ among which the diffusion coefficients of NO and $\mathrm{O}_{2}$ in gas- and liquid-phase $\left(D_{G, i}, D_{L, i}\right)$ were calculated from the Hirschfelder-Curtiss-Bird equation and Wilke-Chang equation. ${ }^{3,4}$ The relation between $E$ and the Hatta number $(H a)$ have been investigated in many literatures, and the $H a$ number in this work is defined as: $:^{5}$

$$
\begin{aligned}
& H a_{i}=\frac{1}{k_{L, i}} \sqrt{\frac{2}{q+1} D_{L, i} C_{L, \mathrm{~F}}^{p} C_{i}^{q-1} k_{p q, i}} \quad(i=\mathrm{X}, \mathrm{Y}) \\
& E_{i}=\left\{\begin{array}{lr}
1, & H a_{i} \leq 0.3 \\
\frac{H a_{i}}{\operatorname{tanhHa}_{i}}, & 0.3<H a_{i} \leq 3 \\
H a_{i}, & H a_{i}>3
\end{array}\right.
\end{aligned}
$$

where $p$ and $q$ represent the orders of the reaction in relation to Fe(II)EDTA and the gas component $i ; k_{p q, i}$ is the kinetic rate constant. Under typical operating conditions, reaction (1) is of first order with respect to Fe(II)EDTA and NO. However, reaction (2) is of first order in $\mathrm{O}_{2}$, but is of first or second order in Fe(II)EDTA depending on its concentration in liquid. ${ }^{6,7}$ The values of the rate constants for reaction (1) and (2) have been thoroughly investigated in our previous work and other 
literatures..$^{5,8,9}$ At steady state, the inlet concentration of Fe(II)EDTA at the top of the reactor equals the outlet concentration. In the calculation of the enhanced factors, $C_{L, \mathrm{~F}}$ was thought to remain unchanged along the tower, because the microbial communities varied along the tower ${ }^{10}$ and the coexistence of chemical reaction and biological regeneration could keep the fluctuation of it within a certain range.

The value of $K$ for reaction (1) was a function of the temperature, which was called van't Hoff equation. The details of $K$ can be obtained according to related research results. ${ }^{11,12}$

The effective gas-liquid interfacial area $(a)$ corresponding to the total physical surface area $\left(a_{t}\right)$ in the packed column under given operating condition can be estimated based on the relationship reported by Onda. ${ }^{2}$ The Henry's constants of NO and $\mathrm{O}_{2}\left(H_{i}\right)$ are given by Shi et al. and Gambardella et al. ${ }^{5,8}$

\section{Monod kinetic parameters estimations}

Generally, for the biological processes, $r_{\max , j}$ and $K_{S, j}$ can be obtained via shaking-bottle incubating test. However, the biomass in the reactor and the diffusion efficiency factor are complicated to be calculated accurately. For the reactor with immobilized cells, taking the biomass and the diffusion in biofilm into consideration, we can use the maximum reducing rate of the component $j\left(R_{\max , j}\right)$ and the half-saturation coefficient $\left(K_{S, j}\right)$ in the scale of reactor to characterize the kinetics of the biological processes. $R_{\max , j}$ and $K_{S, j}$ for different conditions were estimated through batch experiments. To start a batch experiment, $10 \mathrm{mM} \mathrm{Fe(III)EDTA} \mathrm{or} 3$ 
mM Fe(II)EDTA-NO was added into the reactor, and the system was operated for 12 $\mathrm{h}$ under different conditions. The concentration of the substrate was monitored every 30 minutes. The actual reduction rate of Fe(III)EDTA was the sum of the apparent reduction rate and the oxidation rate of $\mathrm{Fe}(\mathrm{II}) \mathrm{EDTA}$ which can be calculated via equations (5), (6), (8), (12), (13), (S2), and (S3). The results are listed in Figure S1 and Table S1.

\section{NOMENCLATURE}

$a \quad$ effective interfacial area, $\mathrm{m}^{2} \mathrm{~m}^{-3}$

$a_{t} \quad$ total physical surface area, $\mathrm{m}^{2} \mathrm{~m}^{-3}$

C concentration, $\mathrm{mol} \mathrm{m}^{3}$ for liquid, $\mathrm{ppm}$ or $\%(\mathrm{v} / \mathrm{v})$ for gas

$D \quad$ diffusion coefficient, $\mathrm{m}^{2} \mathrm{~s}^{-1}$

E enhanced factor

F $\quad \mathrm{Fe}(\mathrm{II}) \mathrm{EDTA}$

$H \quad$ Henry's constant, $\mathrm{Pa} \mathrm{m}^{3} \mathrm{~mol}^{-1}$

$K \quad$ equilibrium constant, $\mathrm{m}^{3} \mathrm{~mol}^{-1}$

$K_{S} \quad$ half-saturation coefficient, $\mathrm{mol} \mathrm{m}^{-3}$

$k \quad$ individual phase mass transfer coefficient, $\mathrm{m} \mathrm{s}^{-1}$

O Fe(III)EDTA

P Fe(II)EDTA-NO

$R_{\max }$ maximum reduction rate in the scale of reactor, $\mathrm{mol} \mathrm{m} \mathrm{m}^{-3} \mathrm{~h}^{-1}$

X NO

$\begin{array}{ll}\mathrm{Y} & \mathrm{O}_{2}\end{array}$

$\eta \quad$ NO removal efficiency

$\delta \quad$ diffusion efficiency factor in biofilm 

Subscripts
$B$ biofilm
$b$ bulk
$G \quad$ gas phase
$L \quad$ liquid phase

\section{Supplementary references}

(1) Onda, K.; Sada, E.; Takeuchi, H. Gas absorption with chemical reaction in packed columns. J. Chem. Eng. Jpn. 1968, 1 (1), 62-66.

(2) Onda, K.; Takeuchi, H.; Okumoto, Y. Mass transfer coefficients between gas and liquid phases in packed columns. J. Chem. Eng. Jpn. 1968, 1 (1), 56-62.

(3) Miyabe, K.; Isogai, R. Estimation of molecular diffusivity in liquid phase systems by the Wilke-Chang equation. J. Chromatogr. A. 2011, 1218 (38), 6639-6645.

(4) Kerkhof, P. J. A. M.; Geboers, M. A. M. Toward a unified theory of isotropic molecular transport phenomena. AIChE J. 2005, 51 (1), 79-121.

(5) Gambardella, F.; Ganzeveld, I. J.; Winkelman, J. G. M.; Heeres, E. J. Kinetics of the reaction of Fe(II)EDTA with oxygen in aqueous solutions. Ind. Eng. Chem. Res. 2005, 44 (22), 8190-8198. (6) Winkelman, J. G. M.; Gambardella, F.; Heeres, H. J. A rate based reactor model for BiodeNO ${ }_{x}$ absorber units. Chem. Eng. J. 2007, 133, 165-172.

(7) Zhang, S.; Chen, H.; Xia, Y.; Liu, N.; Lu, B. H.; Li, W. Current advances of integrated processes combining chemical absorption and biological reduction for $\mathrm{NO}_{\mathrm{x}}$ removal from flue gas. Appl. Microbiol. Biot. 2014, 98 (20), 8497-8512.

(8) Shi, Y.; Wang, H.; Chang, S. G. Kinetics of NO absorption in aqueous iron(II) thiochelate solutions. Environ. Prog. 1997, 16 (4), 301-306. 
(9) Xia, Y.; Lu, B.; Liu, N.; Chen, Q; Li, S.; Li, W. $\mathrm{NO}_{x}$ removal in chemical absorption-biological reduction integrated system: process rate and rate-limiting step. Bioresour. Technol. 2013, 149, 184-190.

(10) Zhang, S.; Chen, H.; Xia, Y.; Zhao, J.; Liu, N.; Li, W. Re-acclimation performance and microbial characteristics of a thermophilic biofilter for $\mathrm{NO}_{\mathrm{x}}$ removal from flue gas. Appl. Microbiol. Biot. 2015, 99 (16), 6879-6887.

(11) Gambardella, F.; Winkelman, J. G. M.; Heeres, H. J. Experimental and modelling studies on the simultaneous absorption of NO and in aqueous iron chelate solutions. Chem. Eng. Sci. 2006, $61(21), 6880-6891$.

(12) Schneppensieper, T.; Wanat, A.; Stochel, G.; Goldstein, S.; Meyerstein, D.; van Eldik, R., Ligand effects on the kinetics of the reversible binding of NO to selected aminocarboxylato complexes of iron(II) in aqueous solution. Eur. J. Inorg. Chem. 2001, 9, 2317-2325. 
(a)

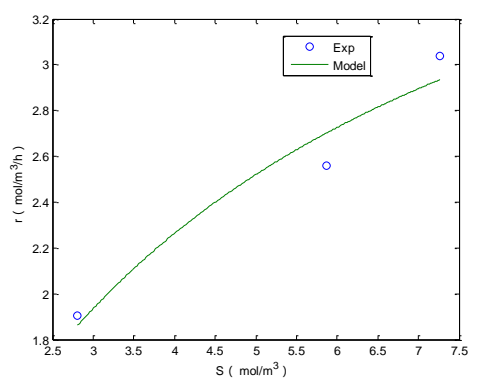

(c)

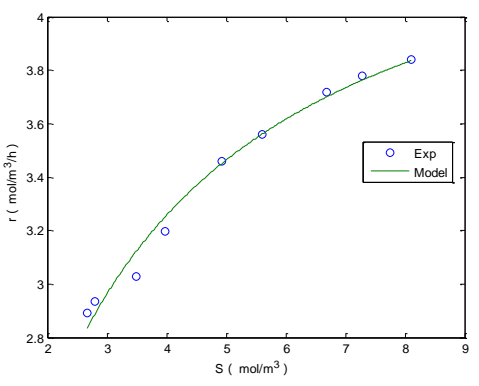

(e)

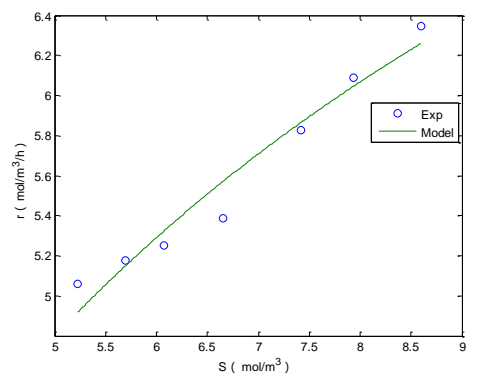

$(\mathrm{g})$

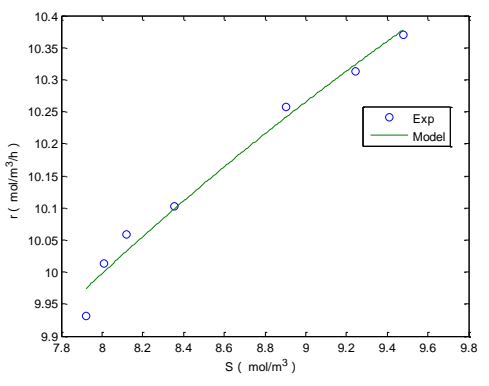

(b)

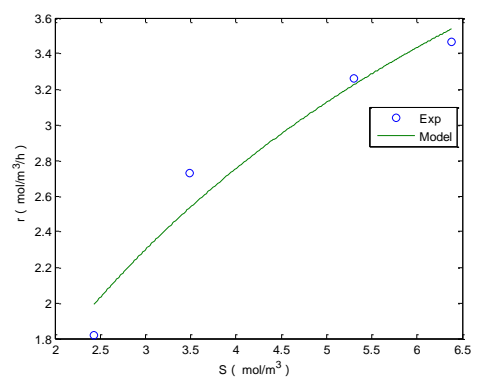

(d)

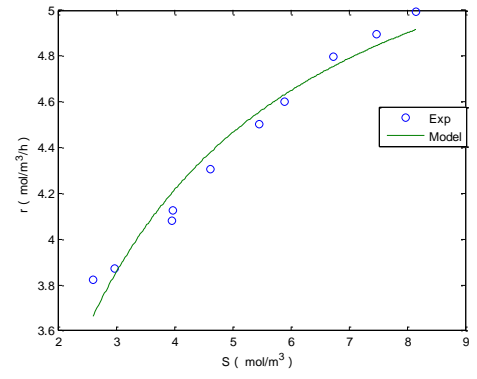

(f)

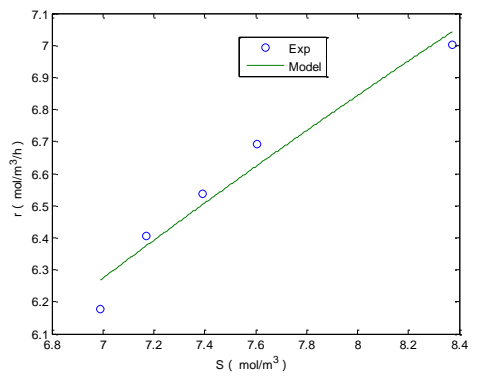

(h)

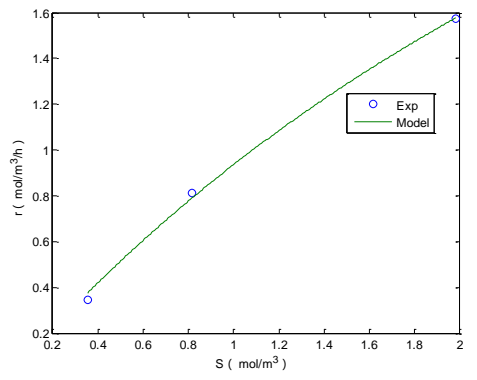

Figure S1. Estimations of $R_{\max , 0}$ and $K_{S, 0}$ under (a) $0 \%(\mathrm{v} / \mathrm{v}) \mathrm{O}_{2}$, (b) $1 \%$ (v/v) $\mathrm{O}_{2}$, (c) $2 \%(\mathrm{v} / \mathrm{v}) \mathrm{O}_{2}$, (d) $3 \%(\mathrm{v} / \mathrm{v}) \mathrm{O}_{2}$, (e) $4 \%$ (v/v) $\mathrm{O}_{2}$, (f) $5 \%(\mathrm{v} / \mathrm{v}) \mathrm{O}_{2}$, (g) $8 \%(\mathrm{v} / \mathrm{v}) \mathrm{O}_{2}$; and $R_{\max , \mathrm{P}}$ and $K_{S, \mathrm{P}}(\mathrm{h}) 0 \%(\mathrm{v} / \mathrm{v}) \mathrm{O}_{2}$. 
Table S1. Main model variables under the typical tested conditions. (NO: $500 \mathrm{ppm}$, $\mathrm{O}_{2}: 3 \%(\mathrm{v} / \mathrm{v}), \mathrm{Q}_{\mathrm{G}}: 2 \mathrm{~L} \mathrm{~min}^{-1}$, $\mathrm{Q} \mathrm{L}: 40 \mathrm{~L} \mathrm{~h}^{-1}$, total iron: $\left.10 \mathrm{Mm}, \mathrm{T}: 323 \mathrm{~K}\right)$

\begin{tabular}{|c|c|c|}
\hline Parameter & Value & Source \\
\hline$H_{\mathrm{X}}\left(\mathrm{Pa} \mathrm{m}^{3} \mathrm{~mol}^{-1}\right)$ & $8.08 \times 10^{4}$ & literature $^{8}$ \\
\hline$H_{\mathrm{Y}}\left(\mathrm{Pa} \mathrm{m}^{3} \mathrm{~mol}^{-1}\right)$ & $1.08 \times 10^{5}$ & literature $^{5}$ \\
\hline \multirow[t]{2}{*}{$D_{G, \mathrm{X}}\left(\mathrm{m}^{2} / \mathrm{s}\right)$} & $2.35 \times 10^{-5}$ & \\
\hline & & calculation ${ }^{4}$ \\
\hline$D_{G, \mathrm{Y}}\left(\mathrm{m}^{2} / \mathrm{s}\right)$ & $2.36 \times 10^{-5}$ & \\
\hline \multirow[t]{2}{*}{$D_{L, \mathrm{X}}\left(\mathrm{m}^{2} / \mathrm{s}\right)$} & $4.42 \times 10^{-9}$ & \\
\hline & & calculation $^{3}$ \\
\hline$D_{L, \mathrm{Y}}\left(\mathrm{m}^{2} / \mathrm{s}\right)$ & $4.20 \times 10^{-9}$ & \\
\hline$k_{G, \mathrm{X}}\left(\mathrm{m} \mathrm{s}^{-1}\right)$ & $2.21 \times 10^{-2}$ & \\
\hline \multirow[t]{2}{*}{$k_{G, \mathrm{Y}}\left(\mathrm{m} \mathrm{s}^{-1}\right)$} & $2.96 \times 10^{-2}$ & \\
\hline & & calculation $^{1,2}$ \\
\hline$k_{L, \mathrm{X}}\left(\mathrm{m} \mathrm{s}^{-1}\right)$ & $1.048 \times 10^{-4}$ & \\
\hline$k_{L, \mathrm{Y}}\left(\mathrm{m} \mathrm{s}^{-1}\right)$ & $1.048 \times 10^{-4}$ & \\
\hline
\end{tabular}


Table S2. The estimated value of $R_{\max , j}$ and $K_{S, j}$

\begin{tabular}{|c|c|c|c|}
\hline substrate & condition & $R_{\max , j}\left(\mathrm{~mol} \mathrm{~m}^{-3} \mathrm{~h}^{-1}\right)$ & $K_{S, j}\left(\mathrm{~mol} \mathrm{~m}^{-3}\right)$ \\
\hline \multirow{7}{*}{ Fe(III)EDTA } & $0 \%(\mathrm{v} / \mathrm{v}) \mathrm{O}_{2}$ & 4.6 & 4.15 \\
\hline & $1 \%(\mathrm{v} / \mathrm{v}) \mathrm{O}_{2}$ & 6.8 & 5.85 \\
\hline & $2 \%(\mathrm{v} / \mathrm{v}) \mathrm{O}_{2}$ & 4.6 & 1.70 \\
\hline & $3 \%(\mathrm{v} / \mathrm{v}) \mathrm{O}_{2}$ & 5.9 & 1.56 \\
\hline & $4 \%(\mathrm{v} / \mathrm{v}) \mathrm{O}_{2}$ & 10.8 & 6.30 \\
\hline & $5 \%(\mathrm{v} / \mathrm{v}) \mathrm{O}_{2}$ & 18.8 & 13.97 \\
\hline & $8 \%(\mathrm{v} / \mathrm{v}) \mathrm{O}_{2}$ & 13.5 & 2.84 \\
\hline Fe(II)EDTA-NO & without inlet gas & 6.4 & 6.11 \\
\hline
\end{tabular}


Table S3 Concentrations of Fe(II)EDTA and Fe(II)EDTA-NO in the case of $10 \mathrm{mM}$ $\mathrm{C}_{\text {TI. }}\left(Q_{G}: 2 \mathrm{~L} \min ^{-1}, Q_{L}: 40 \mathrm{~L} \mathrm{~h}^{-1}, \mathrm{O}_{2}: 3 \%(\mathrm{v} / \mathrm{v}), \mathrm{NO}: 250-1000 \mathrm{ppm}, \mathrm{T}: 323 \mathrm{~K}\right)$

\begin{tabular}{ccccc}
\hline$C_{\text {in }, \mathrm{NO}, \mathrm{ppm}}$ & 250 & 350 & 500 & 800 \\
\hline$C_{\mathrm{Fe}(\mathrm{II}) \mathrm{EDTA}, \mathrm{mM}}$ & 7.09 & 6.99 & 6.83 & 6.48 \\
$C_{\mathrm{Fe}(\mathrm{II}) \mathrm{EDTA}-\mathrm{NO}, \mathrm{mM}}$ & 0.252 & 0.357 & 0.521 & 0.868 \\
$E_{\mathrm{X}}$ & 162.1 & 160.9 & 159.0 & 154.9 \\
\hline
\end{tabular}

